\title{
Pruning date affects bacterial canker of sweet cherry
}

\author{
K.M Colhoun, R.C. Butler and M.V. Marroni \\ Plant E Food Research, Private Bag 4704, Christchurch, New Zealand \\ Corresponding author: virginia.marroni@plantandfood.co.nz
}

The effect of pruning date on the development of canker lesions caused by Pseudomonas syringae pv. syringae (Pss) and P.s. pv. morsprunorum (Psm) was investigated in a field trial using three sweet cherry cultivars with or without Pss and Psm inoculation. Four weeks after treatment, the percentage of twigs showing bacterial canker lesions and the size of lesions were recorded. Overall, the percentage of twigs showing lesions did not vary between cultivars, but did vary with the pruning date and between pathovars. Uninoculated branches pruned in February 2014 did not develop canker lesions. A moderate proportion (40\%) showed lesions when inoculated with Psm and 100\% of twigs showed necrosis when inoculated with Pss. However, for later pruning dates (April and July 2014), the percentage of twigs showing lesions declined progressively for twigs inoculated with both pathovars up to the September pruning. Thereafter, a sharp increase was observed, with nearly $100 \%$ of twigs showing necrosis after the final January 2015 pruning. For branches that showed necrosis, lesion size varied strongly with cultivar, pruning time and pathovar. Lesion size tended to be smaller with later pruning but the pattern varied considerably with pathovar and cultivar. The significance of these findings in relation to bacterial canker management is discussed.

\section{Splash dispersal of Botryosphaeriaceae species in Marlborough vineyards}

\author{
A. Shafi, M.V. Jaspers, H.J. Ridgway and E.E. Jones \\ Faculty of Agriculture and Life Sciences, Lincoln University, Lincoln, New Zealand \\ Corresponding author: amna.shafi@lincolnuni.ac.nz
}

Botryosphaeriaceae species cause dieback and canker in many woody hosts including grapevines, with infection occurring when conidia are released during rainfall and splash borne to pruning and trimming wounds. This study monitored dispersal of naturally released conidia of Botryosphaeriaceae species in three Marlborough vineyards with a Burkard spore trap and rain water traps. Microscopic examination of the Burkard tape and trapped rain water confirmed the presence of Neofusicoccum and Diplodia spp. Species were identified on tape and in rainwater with single stranded conformational polymorphism as $N$. luteum, $N$. parvum/N.ribis, N. australe, D. mutila and D. seriata. To determine conidium dispersal distances, sporulating shoot lesions of N. parvum isolate B2141, for which an isolate specific marker was developed, were placed in one Marlborough vineyard before forecast rainfall periods. The rainwater traps were set up around the sporulating lesions at 0.5 to $20 \mathrm{~m}$ in the direction of the prevailing wind and 0.5 to $5 \mathrm{~m}$ in three other directions. After 2 days rain, Neofusicoccum sp. conidia were identified in the collected rainwater by microscope and with the isolate specific PCR-RFLP (restriction fragment length polymorphism) for N. parvum B2141. This isolate dispersed up to $10 \mathrm{~m}$ in the wind direction and up to $1 \mathrm{~m}$ in the other three directions. 